\title{
Analysis on the Concepts and Theories of the Quality of \\ Graduate Education
}

\author{
Su Zhang (Corresponding author) \\ School of Economics and Management, Changchun University of Science and Technology \\ Changchun 130022, China \\ E-mail: zhangsu1972@163.com
}

$\mathrm{Na} \mathrm{An}$

School of Economics and Management, Changchun University of Science and Technology

Changchun 130022, China

\begin{abstract}
In China, with the sustained development of mass higher education, tutors and staff of graduate school point out that the quality of graduate education tends to decline. In order to solve this problem, lessons must be drawn from the theoretical thinking of predecessors. This paper compiles the concepts and theories of postgraduate, hoping to provide a reference for the quality of graduate education.
\end{abstract}

Keywords: Graduate, Quality of education

Affected by American subprime mortgage crisis in 2008, job seeking of Chinese college graduates is facing the extremely stern situation. In order to escape the pressure of employment, more and more students are applying for the entrance exams of postgraduate, and the number of them increases sharply. As this phenomenon is arising, how to ensure the quality of graduate education is not only an issue that all colleges and universities care and study, but a guarantee of training advanced talents to meet the needs of the country and finishing the task of developing science and technology. Until 2009, the enrolment of postgraduates has reached 1.4 million, accounting for 4.95 percent of the total number of students at the level of higher education. Under such circumstances, only when universities feasibly strengthen and improve the quality of postgraduate education and advance the education innovation, can the manpower and the expertise be produced to meet the requirements of Modern Age.

\section{Quality of education and quality of higher education}

"Quality" originates from a Latin word "qualis", which means "a kind of ". As it is often used in daily life, the word 'quality' can be often sensed and felt. Therefore, "quality" demonstrates not only a certain degree of objectivity but the performance of subjectivity.

\subsection{Quality of education}

Previously, scholars defined the quality of education by adopting the concept of quality that used in management. According to the Educational Dictionary, "the quality of education is the evaluation of educational level and effect", "the achievements in the quality of education will definitely come from the quality of the persons who are educated" and "there are two aims counting in the quality of education. One is the Aim of Education which is to train the persons to possess the basic qualities, while the other one is the Training Aim of all kinds of schools at all levels, which is for the educated to possess specific qualities and to check whether they are qualified."

The author in this paper believes that the quality of education depends on the following aspects: the objective things which refer to the school and academic construction, the subjective things which refer to the teachers and other various of ways of teaching forms, and the students who are educated must accord with the moral demands from society and the requirements of Human Resources from enterprises.

\subsection{Quality of higher education}

In 1998, the first World Higher Education Congress was held in Paris. In this meeting, the World Declaration on Higher Education for the Twenty-First Century: Vision and Action was adopted. As it points out, "quality in higher education is a multidimensional concept, which should embrace all its functions, and activities: teaching 
and academic programmes, research and scholarship, staffing, students, buildings, facilities, equipment, services to the community and the academic environment", "independent national bodies should be established and comparative standards of quality, recognized at international level, should be defined", "due attention should be paid to specific institutional, national and regional contexts in order to take into account diversity and to avoid uniformity", and "quality also requires that higher education should be characterized by its international dimension: exchange of knowledge, interactive networking, mobility of teachers and students, and international research projects, while taking into account the national culture values and circumstance". The author in this paper believes that in the narrow sense, the quality of higher education is the quality of education in the institutions of higher learning; in the broad sense, quality in higher education embraces all educational functions and activities, in which includes scientific research and social education. By means of the higher education, trained talents with highly morality are produced to meet the needs of society.

\section{Quality of graduate education}

Graduate education is normally considered to be a kind of higher education, but it is a bit different. According to the report on the Academic Degree and Graduate Education Strategy, the quality of graduate education refers to the level of the requirements needed by the society is met by the service provided by graduate educational system. The law of higher education in People's Republic of China regulates that through postgraduate education, students will obtain strong theoretical attainments and grasp related techniques in their areas, so that they have practically working capability and capability of doing scientific research. Therefore, the author concludes that, in narrow sense, the quality of graduate education means through postgraduate education, the quality of the educated should meet the requirements of the academic degree and they can use their knowledge to make a contribution for the society. In the broad sense, the quality of graduate education means the students who obtain graduate education should possess capability of doing research. They can self-actualize and they are self-satisfied. Moreover, they meet society's demands and stimulate the harmonious social development.

Postgraduate education is studying for degrees or other qualifications for which a Bachelor's degree is required, which has the characteristics of inquiring learning and speciality. Therefore, basic characters of postgraduate education are to train the students to be inquiry and cultivate their innovation spirit in their fields. And thus the quality of a graduate school will seriously affect the quality of graduate education. Besides, the quality of graduate education has great relevance to the social environment. At present, affected by American subprime mortgage crisis, both the number of students who are applying for the entrance exams of postgraduate schools and the enrollment increase sharply. This kind of phenomenon is aroused by current social environment, and the quality of graduate education will definitely be affected. Consequently, the standard of quality in the graduate education is changing with the development of society. In China, postgraduate education should lay equal stress on the social practice and systematic teaching, so that the quality of postgraduate education can meet social requirements. Moreover, the quality of postgraduate can get further development.

Therefore, not only should the quality of graduate education satisfy self-development, but also it plays an important role in promoting social science, knowledge and theoretical courses. The improvement of quality in the postgraduate education should be done in the light of specific conditions, even from the perspective of history. Consequently, this kind of improvement adapts to training programme and the structure of courses system which are needed in social development, and then the aim of promoting the quality of postgraduate education is achieved. In conclusion, the quality of graduate education is not only relevant to the development of individuals, but also it will affect all aspects that connected with the individuals.

\section{Guarantee of educational quality}

At present, the guarantee of higher educational quality can be divided into three levels by different countries in the world. The first level is macro guarantee of higher educational quality, which refers to the activities that are carried out by the country, society and the institutions of higher education to guarantee the quality; the second level is to conduct the activities from the perspective of institutions of higher education, like universities and colleges; the last level is the activities that are done in the area of teaching to guarantee the higher educational quality.

The author in this paper believes that the guarantee of educational quality is based on the steady improvement of the quality of postgraduate education, and the quality of postgraduate education is a management system established by the world, society and universities, whose purpose is to monitor and control the quality of graduate education. 


\section{Theoretical basis of postgraduate educational quality}

The guarantee of postgraduate educational quality is considered to be a type of engineering system, which should be established on the basis of relevant theories. The basic theories used in this study are as follows: the stage theories of higher education development, the theories of the inner and outer law of education, the theory of social functions in the institutions of higher education and theory of all-round educational quality.

\subsection{The stage theory of higher education development}

The stage theory of higher education development is proposed by Professor Martin Trow at the University of California. He describes the transition in higher education from elite to mass to universal student access. Professor Martin Trow points out that there is a fundamental change from elite to mass, which doesn't only mean a sharp increase in the number of people who can receive higher education, but a change in quality which plays an important role in the transition from elite to mass. The quality refers to the change of education concept, expansion of the function of education, diversity of teaching purposes and forms of Education, and the change of curriculum set-up, the way of teaching, entrance requirement and management. In China, the quantity of graduation has been paid more attention, while the quality of graduate education is ignored, which is harmful to the development of graduate education; and thus, in the process of inspecting postgraduate education, it is necessary to pay more attention to the aspect of quality(Shi, 2010,pp.34-35).

\subsection{Theories of the inner and outer law of education}

As a social activity, education must follow the law. Among all laws, there are two most basic laws. One is the law of relationship between education and social development, which is called the inner law of education. This law holds the idea that education is a subsystem in the whole social system, which has an inevitable connection with other subsystems, like economy, politics and culture. Therefore, this kind of law can be further explained in the following way: education is limited by social economy, politics and culture; in turn, education can stimulate development in education, culture and economy. The other law is about the relationship between education and human beings, which is called outer law of education. This law believes that many factors will affect the learners during the process of education. Two points should be noted in the relation between education and the development of human beings: the first one is that the relation of each composing part in the comprehensive development of human being should be noted, and the second points out that among all composing parts, the relations between educators, educational objects and related influencing factors are the most basic.

The relation between the inner and outer law of education is that the inner law of education is limited by the outer law, while outer law of education can only be done through inner law. Graduate education must follow the inner and outer of education. In other words, social background must be taken into account in understanding the quality of graduate education. It is necessary to measure the quality of graduate education from the aspects of social background, economy, politics, culture and other specific environment. Besides, social factors, such as population, resources, geography and ecology, all need to be taken into consideration. The large-scale development of graduate education is to meet the need of high-level personnel from society, economy, technology and education. To explore the problems of quality in graduate education can not be isolated. Based on the outer law of education, it has to be researched under the historical background of society, economy, technology and education. Similarly, graduate education must follow the law of self-development. By means of a variety of training objectives, the social demand for talents can be met. Besides, following the law of personnel training can promote the comprehensive development of individual student. This is another important theoretical basis that the graduate education must follow.

\subsection{Theory of social functions in the institutions of higher education}

Social functions of institutions of higher education mean that the more advanced social development, the more close relationship between society and universities. Generally speaking, the service provided by the colleges and universities to the society is mainly in the following three ways: to cultivate high-level expertise, to develop science and to serve the community. Based on the "Wisconsin Idea", the service provided by the institutions of higher education for the society and economic development becomes the main function of colleges and universities. During the process of formation of the functions in higher education, training highly qualified specialists is a top priority, which is a basic function, and then the second step is to develop science and serve society. The order of the importance of the three functions is the same with their chronological order. If the function of serving society is put in the first place, institutions of higher education will become service trades. And if the function of doing scientific research is put in the first place, colleges and universities will become disguised research institutions. Therefore, colleges and universities will not change their nature if the function of training talents is in priority. For this reason, study on the quality of the local postgraduate education should 
focus on the quality of talents. Though scientific research and community service are two important functions of institutions of higher education, the function in the quality of personnel training is the most fundamental. The theory functions of higher education tell us that there are varieties of quality standards in the quality of graduate education, but the quality of personnel training is undoubtedly the most important. The guarantee of quality in local postgraduate education is selected for study, which mainly refers to the guarantee of quality of personnel training and the quality of developing science and serving society.

\subsection{Theory of all-round educational quality.}

The implementation of all-round quality management began in western development countries since the early 90 s, and now it is developing quickly. The all-round quality education is the application of all-round quality management in the area of education. After experiencing the traditional "after test-based" quality management and statistical "prevention first" quality management, the third stage of development is formed, whose core concept is the continuing emphasis on quality improvement. It means that an organization, which is based on full participation, treats quality as its centre. All members will benefit from this organization, and thus the organization will achieve long-term success.

All-round quality management places emphasis on the transition of the forms of management, which is shifting from the traditional one-dimensional view of performance to the full range of view on quality. As the continued expansion on the concept of education quality, the quality of education is not only to train students to possess knowledge, but also to help them have other various qualities, such as working attitude, sense of cooperation and competition, professionalism, moral cultivation, environmental adaptability and mental endurance capabilities. Therefore, all-round quality management is not only a philosophy, but a method.

After all-round quality management is applied in the field of education, it emphasizes education as a service which is provided to meet students and their parents" needs, who are considered to be "consumers" and "customers". The internal and external work in the universities should be evaluated from the perspective of service. All-round quality management involves all activities in the school and it is related to everyone. To guarantee the quality of graduate education is to implement a comprehensive management.

\section{References}

Lin, Shi. (2010). The Construction of the Guarantee system of quality in Graduate Education. China Electric Power Edition, 15, 34 -35.

Xiangyang, M. (2009). Change of the Quality Evaluation in Graduate Education. Journal of China University of Geosciences, 3, 58-61.

Yuedong, L. (2010). Reflections on the Security System of Graduate Education. Journal of Sichuan College of Education, 5, 1-3. 